\section{Observation on previous comments on incomplete IUS removal}

A 61-year-old para $1+1$ type 2 diabetic patient attended our walk-in clinic for her intrauterine system (IUS) to be removed. The IUS had been inserted over 10 years previously and she had apparently forgotten about it. She had been amenorrhoeic for at least 6 years, presumably because she had reached the menopause. Examination revealed an atrophic lower genital tract and atrophic cervix, with the IUS threads visible. The IUS was removed but its horizontal arms appeared to be missing

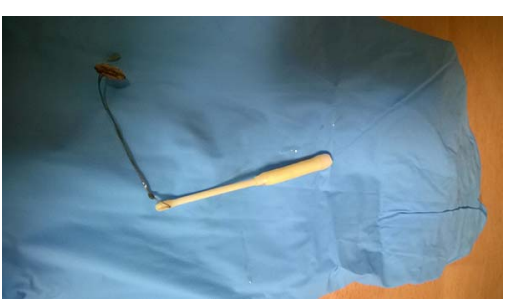

Figure 1 Intrauterine system on removal with no horizontal arms visible.

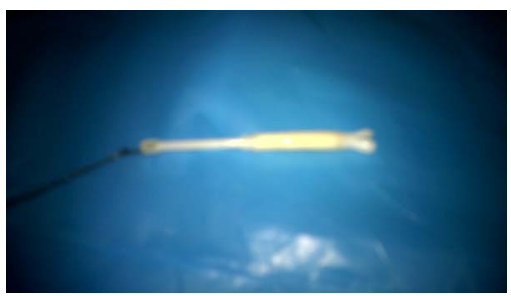

Figure 2 Intrauterine system (IUS) on re-examination with the sleeve in the process of being pulled gently towards the IUS tail.

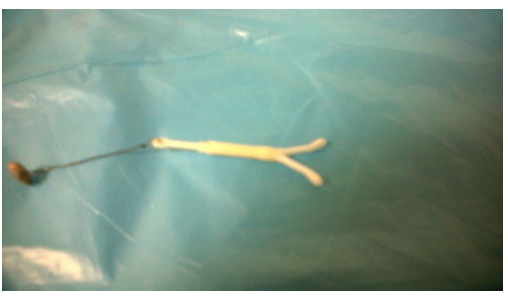

Figure 3 Intrauterine system (IUS) showing the horizontal arms appearing as the sleeve is moved closer to the IUS tail.
(Figure 1). A pelvic ultrasound scan did not locate any foreign body in the uterus, and an abdominal X-ray was normal.

Because this appeared to be an unusual event, the IUS was preserved in formalin.

On reading Brechin's letter ${ }^{1}$ and Alanko et al.'s response ${ }^{2}$ in the October 2014 Journal, the IUS was retrieved, re-examined and the sleeve gently pulled towards the IUS tail (Figures 2 and 3). This clearly showed that the IUS sleeve was covering the horizontal arms. It would appear that during the removal process the sleeve had slid cranially as the IUS was pulled through the internal os and a cervical canal that were presumably narrow due to postmenopausal atrophy.

\section{Disraeli Okoro, MRCOG, DFSRH}

Speciality Doctor, Camberwell Sexual Health Clinic, King's College Hospital, London, UK; d.okoro@nhs.net

\section{Competing interests None.}

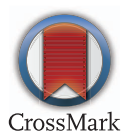

J Fam Plann Reprod Health Care 2015;41:77.

doi:10.1136/jprhc-2014-101143

\section{REFERENCES}

1 Brechin S. Comment on 'Incomplete IUS removal'. J Fam Plann Reprod Health Care 2014;40:309.

2 Alanko M, Hull D, Inki P. Comment on 'Incomplete IUS removal'. J Fam Plann Reprod Health Care 2014;40:309-310. 